\title{
Haemophagocytic Lymphohistiocytosis Associated with Dengue Fever - A case series
}

\author{
Quazi Tarikul Islam ${ }^{1}$, Hirinmoy Barman Sagor ${ }^{2}$, Tasmina Chowdhury Tuli ${ }^{3}$
}

\begin{abstract}
Hemophagocytic lymphohistiocytosis $(H L H)$ is a life-threatening medical condition characterized by hyperphagocytosis secondary to an inappropriate over-activation of macrophages and lymphocytes that driven by excessive cytokines production which resulted in cellular destructions. Dengue induced hemophagocytic lymphohistiocytosis $(H L H)$ is a serious condition and may prove fatal if not detected early and treated appropriately. Diagnosis of $\mathrm{HLH}$ is challenging and usually missed as clinical and laboratory findings are nonspecific. It should be suspected with prolonged fever beyond seven days associated with splenomegaly, hyperferritinemia, worsening cytopenias and development of multiorgan dysfunction. A proportion of patients recovered with supportive therapy, however most required interventions with corticosteroids, intravenous immunoglobulin or chemotherapy. We report 3 cases of dengue associated $\mathrm{HLH}$. Among them 2 patients were treated with steroid with good outcome, and one died from MODS.
\end{abstract}

Key words : Haemophagocytic Lymphohistiocytosis, Dengue, Methylprednisolone, MODS

DOI: https://doi.org// 0.3329/jom.v2 Ii2.50220

Copyright: (C) 2020 Islam QT et al. This is an open access article published under the Creative Commons Attribution-NonCommercial-NoDerivatives 4.0 International License, which permits use, distribution and reproduction in any medium, provided the original work is properly cited, is not changed in any way and it is not used for commercial purposes.

Received: 0 I August, 2020

Accepted: 16 August 2020

\section{Introduction:}

Dengue, transmitted by the mosquito Aedes aegypti affects millions of people worldwide every year. Hemophagocyticl ymphohistiocytosis (HLH), a potentially fatal condition that is often under recognised contributing to its high mortality and morbidity. Early recognition is crucial for any efforts at curative therapy. Virus-associated hemophagocytic syndrome is a disorder characterized by a benign histiocytic proliferation with marked hemophagocytosis in the background of a systemic viral infection. Infection-associated hemophagocytic syndrome carries a high mortality ${ }^{1}$ .Hemophagocytic lymphohistiocytosis (HLH) has a prominent link with a variety of viral, bacterial, fungal, and parasitic infections. It may be diagnosed in association with autoimmune diseases and malignancies such as T-cell lymphomas. ${ }^{2}$ Viral infections mostly implicated in association with HLH are Epstein-Barr virus infection,

1. Professor of Medicine, Popular Medical College, Dhaka, Bangladesh

2. Assistant Registrar of Medicine, Popular Medical College Hospital, Dhaka, Bangladesh

3. Registrar of Medicine, Popular Medical College Hospital, Dhaka, Bangladesh

Corresponding author: Prof. Quazi Tarikul Islam, Professor of Medicine, Popular Medical College, Dhaka, Bangladesh, prof.tarik@gmail.com cytomegalovirus infection, adenovirus infection, and viral hepatitis ${ }^{3}$.We report 3 cases of dengue associated HLH with their management and outcome. The following cases were diagnosed during the outbreak of Dengue Fever between the month of June and September, 2019 admitted at Popular Medical College Hospital.

\section{Description of cases}

\section{Patient 1}

A 40 year old diabetic female from Hazaribag, Dhaka with Dengue NS1 positive presented in August 2019 with fever for 6 days and vomiting, loose motion, pain abdomen for 3 days. Significant findings on examination were fever of $103^{\circ} \mathrm{F}$, hypotension, epigastric and right hypochondriac tenderness, and dullness over both lung bases.

Routine laboratory parameters revealed hemoglobin $10.2 \mathrm{gm} /$ $\mathrm{dl}$, Leukopenia with presence of reactive lymphocytes (WBC count $3.4 \mathrm{~K} / \mu \mathrm{L}$; Lymphocyte $57 \%$ ) and low platelet count $\left(18,000 / \mathrm{mm}^{3}\right.$. There were significant derangements of the biochemical parameters as well. Liver enzymes were elevated, AST 727 U/L and ALT 498 U/L. Serum lipase levels was high $465 \mathrm{U} / \mathrm{L}$, hyponatraemia $(127 \mathrm{mmol} / \mathrm{L})$.

The platelet count dropped to $10 \mathrm{~K} /$ on day two of admission with per rectal bleeding. The patient subsequently received one units of single donor platelet. 
On day 3 of admission patient developed breathlessness and patient WBC count was $19.5 \mathrm{~K} /$. Ultrasound imaging showed mild splenomegaly (measured length $13.5 \mathrm{~cm}$ ), free fluid in abdomen and edematous pancreas and bilateral pleural effusion. Chest X-ray showed pneumonitic changes in both lung fields.

Serum ferritin level done at day 3 of admission was 8040 $\mathrm{ng} / \mathrm{ml}$. Serum procalcitonin level was $3 \mathrm{ng} / \mathrm{dl}$ which indicate sepsis . D- dimer was slightly high but APTT was normal. Serum Triglyceride was $456 \mathrm{mg} / \mathrm{dl}(<150 \mathrm{mg} / \mathrm{dL})$.

Urine and blood cultures were negative. Negative Weil Felix screening test for rickettsial infections, Rapid-test antidengue virus IgM antibody was positive but anti-dengue IgG was nonreactive, which is suggestive of primary dengue infection.

Although bone marrow examination was not done, diagnostic criteria of HLH were met: fever, splenomegaly, cytopenia, hypertriglyceridaemia and hyperferritinaemia .Diagnosis was made Dengue Fever Group C complicated with HLH with pancreatitis and pneumonitis. Intravenous Methylprednisolone was initiated on $10^{\text {th }}$ day of illness $(500 \mathrm{mg} /$ daily), was continued for 3 days and then was changed to oral methylprednisolone $16 \mathrm{mg}$ twice daily for another 5 days. After good clinical improvement the patient was discharged after 8 days of hospital stay. A follow up checkup after 2 weeks showed all results of blood tests were normal.

\section{Patient 2}

A 24 year old male from Cumilla with Dengue NS1 positive presented in September 2019 with fever for 6 days and respiratory distress for 3 days.Initial laboratory investigations showed bicytopenia (Leukopena $3.67 \mathrm{~K} /$ and Thrombo-cytopenia 26,000) and transamiases (ALT 399 U/ L, AST $673 \mathrm{U} / \mathrm{L}$ ).

Ultrasound imaging showed hepatomegaly $(15 \mathrm{~cm})$ and mild splenomegaly (measured length $12.6 \mathrm{~cm}$. Chest X-ray showed feature of pneumonitis. He received empirical antibiotics although later all microbiological investigations were negative. Dengue serology was positive for both IgG and IgM, indicative of secondary dengue infection.

Serum ferritin and Serum Triglyceride level were $6620 \mathrm{ng} /$ $\mathrm{ml}$ and $332 \mathrm{mg} / \mathrm{dl}$ respectively.

Diagnosis was made Dengue Fever Group C complicated with pneumonitis and HLH on the basis of fever, splenomegaly, cytopenia, hypertriglyceridaemia and hyperferritinaemia.

Three days course of Inj. Methyl Prednisolone $250 \mathrm{mg}$ IV daily was given. Resolution of fever, followed by other symptoms and normalization of all blood results occurred. No oral substitution of Prednisolone was given to the patient.

\section{Patient 3}

A 60 year old diabetic and hypertensive male from Maniknagor, Dhaka with Dengue NS1 positive presented in august 2019 with fever for 5 days and yellow discoloration sclera, vomiting, disorientation, pain abdomen for 2 days. Significant findings on examination were fever of 103 , hypotension, epigastric and right hypochondriac tenderness, deeply icteric and feature of hepatic encephalopathy ( Flapping tremor, disorientation).

Initial laboratory investigations showed bicytopenia (Leukopenia $3.60 \mathrm{~K} /$ and thrombocytopenia 13,000/) ), transaminase (ALT $5200 \mathrm{U} / \mathrm{L}$, AST $6873 \mathrm{U} / \mathrm{L}$ ), bilirubin $19.10 \mathrm{mg} / \mathrm{dL}$, s. albumin $2.86 \mathrm{~g} / \mathrm{dL}$, renal impairment (creatinine $6.08 \mathrm{mg} / \mathrm{dL}$, urea $160 \mathrm{mg} / \mathrm{dL}$ ), Lipase $5461 \mathrm{u} / \mathrm{L}$ PT $18 \mathrm{sec}$ (control 12sec), APTT 43sec (control $32 \mathrm{sec}$ ), Ddimer 4.17, FDP 13.68 (RV $-<5$ ), Fibrinogen was normal and $\mathrm{ABG}$ showed metabolic acidosis.

Ultrasound imaging showed mild splenomegaly (measured length $12.7 \mathrm{~cm}$ ), free fluid in abdomen and edematous gallbladder. Chest X-ray showed bilateral pleural effusion. Serum procalcitonin level was $95.21 \mathrm{ng} / \mathrm{dl}$ and lactate was $108.1 \mathrm{mg} / \mathrm{Dl}$ which indicate severe sepsis.

Dengue serology IgM antibody was positive but anti-dengue $\mathrm{IgG}$ was non reactive, which is suggestive of primary dengue infection. All microbiological investigations for secondary infection (Blood, urine and stool culture) were negative.

Viral screening (HAV, HBV, HCV and HEV) were negative.

Serum ferritin and Serum Triglyceride level were 4524ng/ $\mathrm{ml}$ and $365 \mathrm{mg} / \mathrm{dL}$ respectively.

Diagnosis was made as Dengue Fever Group C complicated with Expanded Dengue Syndrome and MOD (hepatitis, pancreatitis, AKI) and HLH on the basis of, splenomegaly, cytopenia, hypertriglyceridaemia and hyperferritinaemia .

Patent was managed at intensive care unit with board spectrum antibiotic, steroid (Methyle Prednisolone $500 \mathrm{mg}$ IV daily for 3 days), aphaeretic platelet transfusion, Haemodialysis. But patient condition deteriorated further and patient died after 9 days of hospital admission.

\section{Discussion:}

HLH is a disease with major therapeutic and diagnostic difficulties. The diagnosis HLH was based on five criteria (fever, splenomegaly, bicytopenia, hypertriglyceridemia and/ or hypofibrinogenemia, and hemophagocytosis). ${ }^{4}$ In 2004 three additional criteria were introduced by the Histiocyte 
Society; low or absent NK-cell-activity, hyperferritinemia, and high-soluble interleukin-2-receptor levels. ${ }^{5}$ Five of these eight criteria must be fulfilled for a diagnosis of HLH. The NK cell activity and soluble IL2 receptor quantitation tests are not done in routine clinical practice.

Bone marrow examination could not be done in our 3 cases. These patients fulfilled five out of the eight criteria - high grade fever, splenomegaly, cytopenia, hypertriglyceridaemia, hyperferritinaemia and accordingly were diagnosed as case of secondary HLH clinically and biochemically. HLH may be primary (familial) and secondary. Secondary HLH develop due to over activation of immune system. Secondary HLH has been associated with a variety of viral, bacterial, fungal and parasitic infections as well as collagen vascular diseases and malignancies particularly T-cell lymphomas ${ }^{6}$. The term reactive HLH has been suggested when HLH is associated with an identifiable infectious or non-infectious etiology to distinguish it from the familial form. Infection has been found to be associated with HLH in half of all reported cases. ${ }^{7}$

Early recognition and diagnosis of HLH might enable physicians to start the steroid treatment in optimal time, leading to better clinical outcome. ${ }^{8}$ Although the mechanism of HLH remains unclear, current accepted theory suggests that inappropriately proliferating and activated T-cells may induce macrophage activation with inadequate intracellular killing of phagocytes. ${ }^{9}$ Many studies suggested the important roles of perforin and natural killer (NK) cells in the HLH subtypes. $^{10}$

In DF the febrile phase lasts up to seven days. With prolonged fever, secondary bacterial infection should be excluded and dengue associated HLH should be suspected. Steroid and immunoglobulin are the mainstay of treatment of HLH. Severe or fatal complications may ensue if dengue associated HLH is unrecognized. Cases received methyl prednisolone due to early recognition of dengue associated HLH based on the presence of persistent fever, splenomegaly, cytopenia, hypertriglyceridaemia and hyperferritinaemia . Case 1 and 2 were successfully recovered with treatment but case 3 did not survived due to development of MOD and Expanded dengue syndrome which encountered the aggressiveness of HLH if not early detected and treated accordingly.

Defervescence occurs between D3 and D7 and in DHF this period is associated with critical phase and plasma leakage. Secondary dengue infection (two sequential infections by different serotypes) is also a risk for severe dengue. We found one case was associated with secondary infection.

Some studies observed that primary dengue infections were as much at risk of severe DHF and dengue associated HLH. ${ }^{4,7,9}$ Case 1 and 3 were associated with primary infection. So, both primary and secondary infection with DF can cause HLH.

It would be important to differentially diagnose dengueassociated HLH from severe dengue hemorrhagic fever. Early recognition and initiation of steroid would be crucial for the successful treatment of dengue fever complicated by HLH. Dengue virus needs to be investigated as an important triggering factor for HLH.

\section{Conclusion:}

Dengue associated HLH must be suspected in the presence of persistent fever beyond day 7, splenomegaly, worsening cytopenias, shock and MOD beyond plasma leakage phase. Exclusion of SIRS and secondary infection is important before initiation of corticosteroids. Early recognition has a significant impact on the management and outcome. Dengue associated HLH may indicate a severe form of dengue infection, and dengue virus needs to be recognized as an important causative agent for HLH.

\section{Limitation:}

BM biopsy needs to be performed to demonstrate hemophagocytosis.

Identification of Dengue virus serotype is very crucial to determine the relationship .

Conflict of interest: None declared.

Funding: There were no sources of funding.

Consent: The patient's informed signed consent was obtained.

\section{References:}

1. Sullivan JL, Woda BA. Lymphohistiocytic Disorders. In: David GN, Ginsburg D, Orkin SH, Look AT, editors. Nathan and Oski's Hematology of Infancy and Childhood. 6th ed. Philadelphia: Saunders; 2003. pp. 1380-81. [Google Scholar]

2. Fisman DN. Hemophagocytic syndromes and infection. Emerg Infect Dis. 2000;6:601-8. [PMC free article] [PubMed] [Google Scholar]

3. Karras A, Hermine O. Macrophage activation syndrome. Rev Med Interne. 2002;23:768-78. [PubMed] [Google Scholar] 
4. Henter JI, Horne A, Aricó M, Egeler M, Filipovich A, Imashuku S, et al. HLH2004: diagnostic and therapeutic guidelines for hemophagocyticlymphohistiocytosis. Pediatr Blood Cancer 2007;48:124-31.

5. Henter JI, Elinder G, Ost A. Diagnostic guidelines for hemophagocyticlymphohistiocytosis. the FHL study group of the histiocyte society. SeminOncol 1991;18(1):29-33.

6. Fishman DN. Hemophagocytic syndromes and infection. Emerg Infect Dis 2000;6:601-8.
7. Reiner AP, Spivak JL. Hematophagichistiocytosis. A report of 23 new patients and a review of the literature. Medicine (Baltimore) 1988;67(6):369-88.

8. George MR. Hemophagocyticlymphohistiocytosis: review of etiologies and management. J Blood Med 2014;5:69-86.

9. Bhatt S, Gething PW, Brady OJ, Messina JP, Farlow AW, Moyes CL, et al. The global distribution and burden of dengue. Nature 2013;496:504-7. 